\title{
Entrepreneurial Learning and the Role of Venture Capitalists
}

\author{
HENRIK BERGLUND***, TOMAS HELLSTRÖM** \& \\ SÖREN SJÖLANDER* \\ *Department of Technology Management and Economics, Chalmers University of Technology, Göteborg, \\ Sweden, ${ }^{* *}$ Centre for Entrepreneurship, University of Oslo, Norway
}

(Accepted 5 March 2007)

\begin{abstract}
This paper develops a model of entrepreneurial learning in order to explain how $V C s$ support the process of entrepreneurial learning and thereby add value to their ventures. We draw on two generic approaches to learning, termed the hypothesis-testing mode and the hermeneutic mode, which turn out to be closely interrelated in such learning processes. The resulting model comprises four categories, which focus on what entrepreneurs learn and how it is learnt: experimentation, evaluation, unreflective action and unverified assumptions. We then use these analytical categories to illustrate how VCs apply their different forms of expertise to increase a venture's value once an investment has been made.
\end{abstract}

KEY WORDS: Entrepreneurial learning, venture capital, hermeneutics, hypothesis testing

\section{Introduction}

Every day, numerous promising entrepreneurs seek out the support of venture capitalists (VCs). Only a few receive such support, and even fewer go on to build successful companies. While much effort has been spent trying to understand the decision to invest, considerably less attention has been paid to how VCs actually support venture development once an investment has been made. In addition, the research on VC value added is mainly descriptive with few attempts at theoretical explanation (Fried and Hisrich, 1995; Wijbenga et al., 2003). This has led to coarsegrained quantitative studies and a concomitant failure to conclude whether VCs typically add non-financial value (Busenitz et al., 2004). To help remedy this situation, researchers repeatedly call for more nuanced conceptualizations of VC expertise and venture support - including how different aspects of VC expertise may support specific venture activities at different stages of venture development (cf. Busenitz et al., 2004).

Correspondence Address: Henrik Berglund, Department of Technology Management and Economics, Chalmers University of Technology, S-41296 Göteborg, Sweden. Tel: +46 708128 138; Fax: +46 317721917 ; Email: henber@chalmers.se 
This paper develops such a conceptualization by focusing on how VCs can aid the process of entrepreneurial learning. ${ }^{1}$ More specifically, we develop a theoretical model of entrepreneurial learning and then go on to show how different forms of VC expertise can help support this learning process. The main point of departure is that entrepreneurs have to acquire new knowledge in order to develop their ventures. To explain entrepreneurial performance, we must therefore understand the process by which relevant knowledge is acquired (Minniti and Bygrave, 2001). One among several key issues here is how entrepreneurs interact with external stakeholders - a process in which the VC is often central. While some attempts have been made to model how knowledge is transferred between VCs and ventures (e.g. De Clercq and Sapienza, 2001), this paper downplays such direct learning. Instead focus is put on how knowledgeable VCs help their ventures develop by supporting the process in which entrepreneurs acquire relevant knowledge on their own. Stated differently, we examine how VCs can help facilitate the process of entrepreneurial learning.

To achieve this, the paper is organized as follows. First we discuss the nature of VC expertise, and divide such expertise into general and industry-specific. Building on generic approaches to scientific development, we then discuss two approaches to entrepreneurial learning, which we term the hypothesis-testing mode and the hermeneutic mode respectively. These learning modes can be found in conceptual economic analyses of entrepreneurship as well as in specific contributions to the field of entrepreneurship studies. These accounts pave the way for a synthesizing discussion of entrepreneurial learning in general, and of how VCs can contribute to entrepreneurial learning in particular.

\section{The Nature of VC Expertise}

According to financial theory, the standard debt contract constitutes the most efficient form of financing under normal economic conditions (cf. Gale and Hellwig, 1985). However, information asymmetries and the inherent uncertainty of entrepreneurship prevent the crafting of complete contracts that cover all future contingencies (Grossman and Hart, 1986). Because of moral hazard, only knowledgeable investors who can monitor and influence the venture will invest. The moral hazard also goes in the other direction, as ventures that depend heavily on the entrepreneur's personal human capital are unlikely to accept external advice unaccompanied by a strong financial commitment (Casamatta, 2003). Financial theory thus argues that VCs must possess relevant expertise, especially when investing in uncertain and innovative ventures. Empirical studies of VC involvement reach similar conclusions. Surveys of both VCs and entrepreneurs consistently indicate that VCs are seen as most important in innovative early stage ventures, when the entrepreneur has limited experience and when VCs hold a relatively large equity share (cf. Timmons and Bygrave, 1986; Sapienza, 1992). Together these results indicate that VCs need to possess relevant expertise to fulfil their role towards portfolio companies. Expertise in this context is that on which VCs trade; in other words, it is the principal content in terms of information, qualified understanding and interpretations, which is transferred and transformed as the VC aids venture learning. Following a common division in the literature, we distinguish between 
industry-specific and more general forms of VC expertise (cf. Jungwirth and Moog, 2004; Dimov and Shepherd, 2005). ${ }^{2}$

\section{Industry-Specific VC Expertise}

$\mathrm{VC}$ expertise is often specialized in the sense that it concerns factors operating in a particular industry. Therefore it is typically based on a specific technological field, a limited market and even a certain geographical area (Anderson, 1999). In the first instance, experienced VCs may therefore possess technical expertise that can provide firms with guidance and direct assistance in developing and improving technical solutions. In terms of market expertise, VCs can help identify and develop appropriate business models, identify relevant markets and marketing activities - as well as providing access to networks locally and across distances, thereby contributing valuable new contacts (Sjögren and Zackrisson, 2005). In this way, the VC's network complements that of the entrepreneurs' in important respects. VC networks are often a source of unique market information and of candidates for employment on both high and low levels, as well as of specialized service providers (Fried and Hisrich, 1995). VCs also help ventures promote themselves and get in contact with financiers, thus increasing their likelihood of securing additional funding (Gomez-Mejia et al., 1990). Industry-specific VC expertise is also relevant for strategy formulation and implementation, which may be particularly salient if the strategy hinges on unique offers and differentiation rather than on cost efficiency. This is because such strategies require knowledge of the needs of suppliers and buyers, of potential substitutes and of competing offers - knowledge that the VC is often more likely to possess (Sapienza, 1992). These types of knowledge pertain to specific areas of relevance, with which a VC becomes acquainted after a certain time in a field of industry. Beside such industry-specific knowledge, experienced VCs who have seen many ventures will gradually develop a more general form of venture development expertise.

\section{General VC Expertise}

The possession of general VC expertise complements industry-specific knowledge and is potentially more valuable, especially to entrepreneurs without managerial experience. Indeed, apart from funds, one of the main selling propositions of VCs is their hard-earned and potentially generalizable expertise when it comes to developing innovative ventures. The assumption that such expertise may be present underlies much of the literature on organizational learning, and it suggests that VCs who have been involved in a range of ventures will be able to bring their broad experiences to bear on subsequent decisions and activities (Zacharakis and Meyer, 1998; Busenitz et al., 2004). The argument is that experiences from both successes and failures will have provided the $\mathrm{VC}$ with a general understanding of which principles for action, constellations of people and resources, types of support, etc., work and which do not in a particular situation. Such expertise is typically tacit and therefore hard to imitate, making it a basis for sustainable competitive advantage among VCs (Dimov and Shepherd, 2005).

Besides giving direct advice, an experienced VC can provide legitimacy and comfort to less experienced CEOs and be a source of stability to the board of a new 
venture. This brings to mind the non-instrumental roles that VCs often come to play, for example those of mentors, confidants and friends, which are brought out in interviews with entrepreneurs (MacMillan et al., 1989). A related contribution is the discipline that VCs often bring to the venture development process. VCs know the importance of staying on course, and try their best to pressure entrepreneurs to perform in accordance with jointly established objectives, when it is relevant to do so. If such managerial discipline is not maintained, VCs will often step in and even replace the CEO if needed (Fried and Hisrich, 1995). Generally speaking, VCs often know from experience how to handle complex, interdependent organizational issues such as hiring and firing personnel, managing internal conflicts, and providing overall structure to emerging organizations.

Even if knowledgeable VCs have a lot to offer, time constraints will not allow them to become too operative in their ventures (Gifford, 1997). Instead, VCs prefer to invest in ventures led by entrepreneurs who are flexible and fast learners. This allows VCs to act more as learning coaches and elicitors of knowledge, and it demands less in terms of direct knowledge transfer (Hellmann, 2000).

\section{The Two Modes of Entrepreneurial Learning}

It is apparent that experienced VCs possess knowledge that in different ways can support entrepreneurial learning. In order to better understand the specifics of this relationship, we have to take a closer look at the processes of entrepreneurial learning. ${ }^{3}$ We will essentially argue that entrepreneurial learning can be broken down into two learning modes which are closely related - an insight that has consequences for how to structure this relationship in time.

Traditional economic theory tends to assume maximizing behaviour within given markets, thereby making entrepreneurship and learning quite marginal phenomena (Baumol, 1968; Bianchi and Henrekson, 2005). As a result, many entrepreneurship scholars have come to embrace the more dynamic perspective of the Austrian school of economics (e.g. Shane and Venkataraman, 2000; Minniti and Bygrave, 2001). In this tradition, markets are seen not as given entities, but rather as open-ended processes shaped by entrepreneurial discovery and learning (Hayek, 1978). Israel Kirzner has especially focused on the role of entrepreneurs, but describes the entrepreneur as an economic ideal type to the detriment of a more practical understanding (cf. Kirzner, 1973, 1997).

In what follows we attempt such a practical understanding of entrepreneurial learning, by utilizing inroads to the problem provided by the work of two of Kirzner's younger colleagues. The first of these, David Harper, describes how entrepreneurs learn by systematically testing and evaluating their business ideas in the marketplace (Harper, 1996). The second, Don Lavoie, instead tries to understand how entrepreneurs identify opportunities by emphasizing individuals' cultural embeddedness (Lavoie, 1986, 1991). Both authors extend Kirzner's notion of entrepreneurial alertness and emphasize learning as the general guiding principle. Yet they differ in terms of how learning is to be translated into secondary principles, i.e. the actual process of entrepreneurial learning. These differences derive from the authors' philosophical antecedents. Harper explicitly builds on Karl Popper's (1963) approach, in which learning is the outcome of discrete tests of hypotheses, and where 
knowledge must live up to quite rigorous demands. Lavoie instead invokes Hans-Georg Gadamer (1976) and the hermeneutic tradition, in which learning consists of a gradually developing holistic pre-understanding of a phenomenon, and where learning processes are more fluid, dialogical and difficult to formalize. Harper's and Lavoie's divergent views of entrepreneurial learning are described next in some detail, and related to the respective traditions in which they operate. This general discussion is also complemented with more practical findings from management and entrepreneurship studies.

\section{Learning by Hypothesis Testing}

David Harper (e.g. 1996) seeks to build a theory of entrepreneurial learning based on Karl Popper's theory of scientific development. Harper distinguishes his analysis from the discovery of new entrepreneurial opportunities. Following Popper, he instead describes the logical procedure of how to enact them: 'The Popperian programme takes the realm of logic and methodology (i.e. the context of justification) as the appropriate domain for philosophical analyses of the process by which knowledge grows. It does not take into account psychological, sociological and historical factors (i.e. the context of discovery)' (Harper, 1996, pp. 31-32).

On this account, entrepreneurs learn but never take their theories to be true. Rather, entrepreneurial learning is achieved by stating assumptions speculatively, like guesses or hypotheses, which may be overthrown in the light of opposing evidence or corroborated, i.e. be temporarily accepted (Popper, 1963). Revisions are the key activity for people operating within such a tradition, and Popper suggested the following model for how a discipline or a theory develops, which can also be used to describe certain aspects of entrepreneurial learning:

\section{problem $1 \rightarrow$ tentative theory $\rightarrow$ falsification attempt or error elimination $\rightarrow$ refinement of theory $\rightarrow$ problem 2}

The model suggests that learning starts with a problem being encountered. In our context, this could be an attempt to exploit a window in the market or to capitalize on a new scientific discovery. A set of hypotheses for how to solve the problem is then constructed. The entrepreneur puts these hypotheses to the test in the entrepreneurial situation, by examining technological feasibility, testing product ideas on presumptive customers, trying out business models, etc. What is left after such tests have been performed is a revised version of the problem, or perhaps a new set of hypotheses, should the original ideas not have panned out at all. Harper (1999) takes the entrepreneurial decisions to be sequential, quite in line with what Popper prescribed for science.

Harper's model thus rejects the notion of long-term planning in entrepreneurship, but: 'Like Ansoff's (1965) classic model of corporate strategy, the GK [growth of knowledge] approach would assume that an entrepreneurial team relies upon comprehensive logical analysis in determining strategy' (Harper, 1996, p. 350). A number of management writers have developed more hands-on suggestions for entrepreneurial management along these lines. Like Popper and Harper, these authors 
emphasize rigorous planning, testing and revising of hypotheses. This differs from planning in traditional business projects where deviations from the plan are seen as bad. New ventures, it has been argued, should instead design for systematic failure (Sitkin, 1992) and embrace deviations as opportunities for learning (Sarasvathy, 2001). This does not imply that demands on method and rigour are relaxed. On the contrary, this approach 'imposes disciplines different from, but no less precise than, the disciplines used in conventional planning' (McGrath and MacMillan, 1995, p. 45).

Clearly in the Popperian tradition, McGrath and MacMillan (1995) suggest that entrepreneurs ought to structure the gradual development of their ventures by using four discovery-driven planning documents, themselves akin to compound hypotheses. First, entrepreneurs should create a reverse income statement. Backtracking from required (read hypothetical) profits, margins and sales volumes, entrepreneurs may roughly estimate the potential value of venture success. Second, the venture idea is broken down into pro forma operations specs, identifying underlying assumptions and, as far as possible, testing them in theory. In this manner, the entrepreneur can develop a reasonable estimate of the venture and assess the order of magnitude of its challenges. Third, a key assumptions checklist is developed. This is important to ensure that the critical assumptions on which the venture is based (as hypothesized in the pro forma operations specs) are flagged, discussed and checked as the venture unfolds. Finally, the assumptions are operationalized in a milestone planning chart which specifies how and in what order the critical assumptions should be tested. These planning documents are used to structure entrepreneurial learning, and should be seen as a collection of hypotheses which are continually revised as tests unfold.

Furthermore, Sull (2004) proposes an explicitly Popperian approach to business development that consists of three sequential steps. First, the entrepreneur should formulate a working hypothesis of what the opportunity is, what resources are required, what value the business may create, and how this value may be realized. It is especially important to identify potential deal killers and key drivers of success. Next, the entrepreneur should assemble the resources necessary to conduct experiments. This step is not part of the traditional Popperian framework, but is critical to entrepreneurship. As a general rule, entrepreneurs should only assemble enough capital to conduct the most critical experiments. This is because too much capital may affect discipline and lead to sloppy behaviour, e.g. neglect of potential deal killers. Finally, entrepreneurs should design and run experiments with the goal of reducing the sources of uncertainty that are critical to the success of the new venture.

In the hypothesis-testing tradition, the context of discovery is only briefly touched on before the authors lay out the 'normative set of rules' (Harper, 1999, p. 8) that should guide the testing and evaluation of the discovered ideas. Sull (2004) states that the entrepreneur 'begins the process by formulating a hypothesis' (p. 72) but explicitly leaves it for others to elaborate 'the creativity to envision new things' (p. 76). McGrath and MacMillan's discovery-driven planning similarly aims at 'converting assumptions into knowledge' (McGrath and MacMillan, 1995, p. 44) but says very little about where the initial assumptions come from. Also Popper and Harper acknowledge that the context of discovery demands social and psychological 
insights that fall outside the realm of the hypothesis-testing logic (Popper, 1963; Harper, 1996, pp. 31-32). Since creative discoveries are a fundamental aspect of real-life entrepreneurship, we therefore turn to hermeneutic perspectives on learning.

\section{Hermeneutic Learning}

Harper assumed that the entrepreneurial context of justification, which is his focus, is independent of the entrepreneurial context of discovery (Harper, 1996, p. 32). Lavoie instead focused on the context of discovery, and sought to better understand why entrepreneurs notice some but not other opportunities (cf. Lavoie, 1990; Boettke et al., 2004). Lavoie argued that when entrepreneurs notice opportunities, which is required before any kind of hypothesis may be formulated, they do this from within their set of background assumptions and pre-understandings, and that these form the basis for any understanding of the world. From this perspective, entrepreneurial learning is not equivalent to intractable alertness, followed by a rational process of weeding out faulty hypotheses. Instead, discovery rests on structured yet often tacit pre-understanding, and it is the development of this preunderstanding that guides the process whereby entrepreneurs gradually make sense of the world around them. As Lavoie puts it: 'The seeing of profit opportunities is a matter of cultural interpretation. And like any other interpretation, this reading of profit opportunities necessarily takes place within a larger context of meaning, against a background of discursive practices, a culture' (Lavoie, 1991, p. 36). Despite their intractability, the components and processes of entrepreneurs' pre-understanding can be structured and described, albeit roughly and tentatively - a task taken on by sociologists and philosophers such as Hans-Georg Gadamer, Alfred Schutz and Thomas Luckmann. ${ }^{4}$

The hermeneutic approach to learning encompasses two general aspects. First, the pre-understanding of the actors involved, or alternatively their network of more or less tacitly held assumptions about the world. Second, the process by which this preunderstanding is transformed. In the first case, one may fruitfully draw on Alfred Schutz' and Thomas Luckmann's concept of a 'stock of knowledge', as developed in The Structures of the Life-World (1973). Schutz and Luckmann argued that the stock of knowledge of a person or a collective is built up over time and consists of various sets of cognitive and emotional pointers. These pointers are topical and focus a person's attention on certain themes, interpretative in the sense that they confer meaning on experiences and objects, and finally motivational regarding when and how the actor is stimulated into action. The notion of stock of knowledge is a good starting point for grasping the dimensions of understanding in which hermeneutic learning takes place. A person's stock of knowledge is also, according to Schutz and Luckmann, made up of types and categories - more concrete and often explicable representations of objects and relations in the world, for example of hierarchies of things. Contrary to the linear process of the hypothesis-testing approach, the buildup of hermeneutic knowledge has been described as a circular movement where understanding any aspect requires knowledge of the greater context of which it is a part, and vice versa (Gadamer, 1976).

In line with this, Brown and Duguid argue that central to both innovation and learning is the gradual development of a 'new way of seeing' or a new interpretative 


\section{$172 H$. Berglund et al.}

view (Brown and Duguid, 1991). Such processes are often social and cannot be fully planned. Therefore it is important to establish and nurture 'generative relationships' which provide the settings and collaborative milieus in which learning and innovation can take place (Lane and Maxfield, 1996). Contrary to the Popperian assumption that the entrepreneur first sets up and then tests abstract hypotheses, this tradition argues that action in important ways precedes cognition, and that learning and sense-making instead occur when: 'a flow of organizational circumstances is turned into words and salient categories' (Weick et al., 2005, p. 409). This form of learning can be said to be especially relevant in entrepreneurial contexts, where often very little of consequence is prestructured in abstract propositional form. Gartner, for example, argues that emerging organizations are characterized by ambiguity, and that the role of the entrepreneur is to gradually learn how to cope with this ambiguity by developing ever more plausible interpretations of the future (e.g. Gartner et al., 1992, 2003). Learning is thus not a matter of systematically piecing together snippets of truth about the world, but of arriving at more reasoned and useful interpretations: 'there is no such thing as a representation that is true or false, there are simply versions that are more or less reasonable' (Weick, 1979, p. 169). Similarly, Baron (2006) invokes research on human cognition, more specifically pattern-matching, to describe how entrepreneurs over time are able to "connect the dots' between disparate aspects of the world and thereby gradually discern the emergent patterns that are said to constitute business opportunities. ${ }^{5}$ These theories of gradually evolving pre-understanding, reasonable interpretations, or patternmatching all suggest a more dynamic understanding of the notion of prior knowledge than is usually assumed in the literature (cf. Shane, 2000).

Since entrepreneurship is a practical activity, mere interpretations of the past are not enough. As suggested above, ill-structured pre-understanding often provides the only impetus to act in situations where fully elaborated plans or hypotheses are not available. Pre-understanding is thus critical because it allows the entrepreneur to 'act as if' the future is given, which in turn provides new grist for learning and sensemaking (Gartner et al., 1992; Garud and Karnøe, 2001). In the face of uncertainty, action as such may even become a goal in itself as the entrepreneur 'acts his/her way out of uncertainty' (Hellström et al., 2002, p. 281). An important part of the hermeneutic logic is thus that acting often precedes thinking. Entrepreneurs do not develop hypotheses which are then tested. Instead, actions lead to refined preunderstanding through an iterative process of enactment, sense-making and enactment, directed by and adding to a growing stock of knowledge.

\section{Summary and Comparison}

Both the hypothesis-testing and hermeneutic modes of learning comprise reflection and action, but in different ways. In the hypothesis-testing mode, the learning process starts with reflection which leads to action, whereas in the hermeneutic mode action often precedes learning and reflection. They also differ in the emphasis placed on testing specific hypotheses and on developing more holistic forms of preunderstanding, as well as in the roles assigned to individuals and groups. Table 1 summarizes and compares the two modes of learning along these and other relevant dimensions. In the following section, the two are brought together and drawn on to 
Table 1. Summary of important differences between hypothesis-testing and hermeneutic views of learning

\begin{tabular}{|c|c|c|}
\hline & Hypothesis-testing & Hermeneutic \\
\hline $\begin{array}{l}\text { Aspect of } \\
\text { entrepreneurial } \\
\text { learning in focus }\end{array}$ & $\begin{array}{l}\text { Mainly focused on the context } \\
\text { of justification, and finalized } \\
\text { pieces of knowledge }\end{array}$ & $\begin{array}{l}\text { Mainly focused on the 'ongoing' } \\
\text { and unfolding context of } \\
\text { discovery }\end{array}$ \\
\hline $\begin{array}{l}\text { Role of planning } \\
\text { in the learning } \\
\text { process }\end{array}$ & $\begin{array}{l}\text { Cognition precedes and } \\
\text { determines action in the form } \\
\text { of explicit learning } \\
\text { experiments }\end{array}$ & $\begin{array}{l}\text { Action, loosely based on tacit pre- } \\
\text { understanding, precedes sense- } \\
\text { making and leads to refined pre- } \\
\text { understanding }\end{array}$ \\
\hline $\begin{array}{l}\text { Social direction of } \\
\text { the learning } \\
\text { process }\end{array}$ & $\begin{array}{l}\text { Learning is developed by } \\
\text { individuals and shared to } \\
\text { collectives }\end{array}$ & $\begin{array}{l}\text { Learning is developed collectively } \\
\text { but articulated by individuals }\end{array}$ \\
\hline $\begin{array}{l}\text { Rigidity of the } \\
\text { learning process }\end{array}$ & $\begin{array}{l}\text { Learning is rigidly structured } \\
\text { with focus on testing isolated } \\
\text { hypotheses }\end{array}$ & $\begin{array}{l}\text { Learning is emergent and results } \\
\text { in interrelated forms of } \\
\text { understanding }\end{array}$ \\
\hline
\end{tabular}

elaborate a synthetic framework of entrepreneurial learning, which will allow a pointed discussion of the role of VCs.

\section{A Synthetic Model of Entrepreneurial Learning}

The literature review discussed the nature of $\mathrm{VC}$ expertise and two approaches to entrepreneurial learning. The $\mathrm{VC}$ has been described as an expert who possesses both industry-specific and general venture development knowledge. It has also been argued that, similarly to knowledge creation in science, entrepreneurial learning can be expressed in terms of two main approaches, namely the hypothesis-testing mode, with short feedback loops and factual updating of knowledge, and the hermeneutic mode, which affects understanding of more fundamental aspects of the field of activity. Drawing on these arguments, we now combine the two modes of entrepreneurial learning into one synthetic model, which allows us to discuss in more detail how VCs can bring their expertise to bear on the process of venture development. The model (Figure 1) shows how the core analytical precepts of hypothesistesting and hermeneutic modes of learning relate to each other through a number of actions and dispositions present in the process of entrepreneurial learning, where the weight of each mode shifts according to subjective and situational conditions.

The focus is on describing the process of entrepreneurial learning through time. The arrows illustrate how hypothesis-testing action and the development of hermeneutic pre-understanding interact in the ongoing process of knowledge build-up. Hypothesis-testing action in this context denotes entrepreneurs 'acting in the world', typically carrying out planned experiments, in contrast to reflection that challenges and changes one's pre-understanding, which often entails evaluating the results of such experiments.

The notion that reflection and action are related parts of skilful practice is not new. Schön famously collapsed planning and execution of action through the 


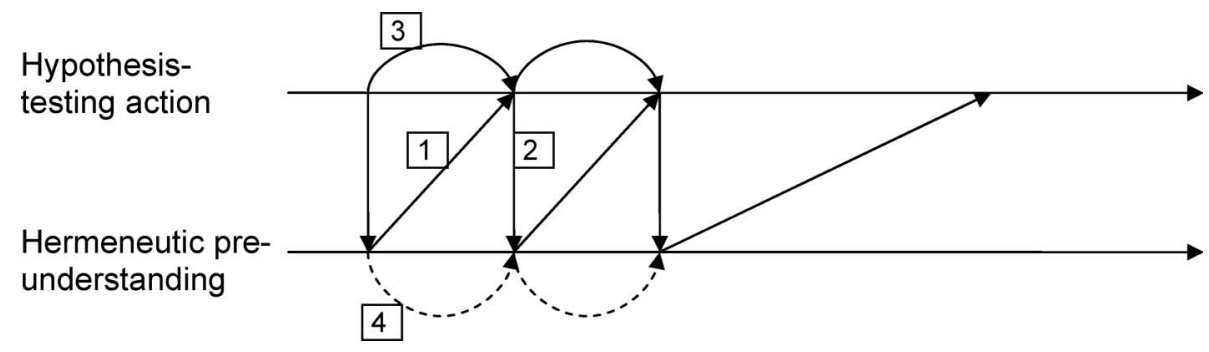

Figure 1. A synthetic model of entrepreneurial learning. Note: $1=$ Experimentation; $2=$ Evaluation; $3=$ Unreflective actions; $4=$ Unverified assumptions

concept of reflection-in-action (Schön, 1983). Others have instead argued for the value of maintaining them as theoretical categories and focusing on their interrelationship (cf. Cook and Brown, 1999). ${ }^{6}$ In addition to the two main arrows, Figure 1 contains four types of within-and-between transfers that make up the core processes of entrepreneurial learning:

(1) Experimentation

(2) Evaluation

(3) Unreflective actions

(4) Unverified assumptions

Drawing on the literature review, we will now go through these four processes in turn and for each of them describe how VCs may support entrepreneurs' learning efforts. It will be clear that these categories are conditioned on both of the main modes of learning discussed, but to different degrees and with different consequences.

\section{Experimentation}

Based on a given pre-understanding anchored in prior experiences, the VC may formulate and subsequently test hypotheses that are relevant to the venture. Such experiments aim at confirming or rejecting assumptions about technologies, markets, the venture's business model or strategy, etc. When designing experiments, it is important to recognize the limited planning horizons that characterize innovative ventures (Lane and Maxfield, 1996). The guiding principle is therefore procedural rationality, in the sense that experiments should be designed to target the most important assumptions or areas of uncertainty - and to do this in a timely manner, given the venture's available resources (McGrath and MacMillan, 1995; Sull, 2004). It is also important that hypotheses are not very complex and do not take too long to complete. For example, if an entrepreneurial experiment simultaneously tests multiple assumptions and the interactions among them, it will be difficult to establish causality, which in turn reduces the experiment's learning potential (Sull, 2004). Experiments must also be cost-efficient, since new ventures often have limited resources. As part of the ambition to optimize learning, entrepreneurs should try to minimize slack and avoid activities with unclear goals. 
When designing entrepreneurial learning experiments, there are important lessons to be learned from other forms of experiment design. For instance, qualitative research design (Yin, 1994) suggests that entrepreneurs may benefit from using:

(A) a critical case approach, if the goal is to get the maximum amount of information from a single experiment when resources are scarce, or else to test the limits of an assumption's validity;

(B) a maximum variation approach, if the goal is to identify central themes or commonalities in diverse data; or

(C) an extreme case approach, to find out more about exceptional successes, unusual situations or otherwise extreme phenomena that may provide relevant learning opportunities for the venture.

VCs are invaluable for this phase and serve a number of functions. First, drawing on their industry-specific expertise, VCs can help identify important issues and assumptions that need to be addressed. In this process, VCs can also take care of certain hypotheses early on, based upon personal experience or a quick phone call to someone in their network. Second, drawing on their general venture development expertise, VCs can help design experiments and also suggest ways to execute these (Busenitz et al., 2004). The selective provision of resources constitutes an alternative, less hands-on tool. As mentioned, too much slack should be avoided since it may induce sloppy behaviour and unnecessary waste (cf. Sull, 2004). By making funds conditional on certain behaviours, VCs therefore are in a position to exert some discipline over entrepreneurial behaviour (Fried and Hisrich, 1995). As is clear from the model, experimentation always builds on a certain pre-understanding. This is actually an important rationale for considering the role of VCs in venture learning, and for taking seriously the assumption that entrepreneurial and VC ways of experimenting differ due to previous hermeneutic learning.

\section{Evaluation}

After a hypothesis has been tested in action, the results are evaluated and incorporated into a new hermeneutic pre-understanding or 'way of seeing' (Brown and Duguid, 1991). The results of practical experiments are thus not only relevant in terms of the specific insights they produce. Each experiment also helps the entrepreneur to form a more nuanced image of the venture's opportunity and general business context. The new pre-understanding provides a basis for reconfiguring the venture and, by doing so, also forms the basis for additional learning experiments.

Here VCs fill a key role as 'decoders', since results must be evaluated within a rich understanding of the overall business situation. In this process, VCs can help entrepreneurs make sense of the outcome of a particular experiment by relating it to their previously acquired expertise, either in the sense of general venture expertise or, perhaps more importantly, in terms of their industry-specific understanding. A knowledgeable VC may be especially useful in evaluating unexpected outcomes, 
such as strange customer responses and suggestions, that may otherwise be ignored (cf. Sull, 2005). VCs can also help to interpret serendipitous events or unreflective actions (see below), which are not the results of planned experiments. Regardless of what triggers it, the process of evaluation is likely to result in reconfiguration of the venture and further practical experiments, thereby creating a continuous movement between experimentation and evaluation.

\section{Unreflective Actions}

Sometimes entrepreneurs act without a clear and explicit purpose, for example due to lack of focus or as a result of routine or 'standard operating procedures'. Following the arguments above, this is potentially wasteful since unplanned actions do not explicitly target issues that are important to the venture; a purposeful action has a higher likelihood of generating learning than an unreflective one. Still, it is likely that this type of action must be accepted to some extent, partly because it is unavoidable but also because the uncertain character of innovation implies that decisions often have to be taken without what could be considered a rational analytical basis' (Monsted, 2006, p. 18). To some extent, entrepreneurial action requires a leap of faith. Indeed, many researchers see this type of 'irrational' action as essential and even defining of entrepreneurship: 'without some unsubstantiated enthusiasm, many ventures would never be started or would quickly die following their start-up' (Busenitz and Barney, 1997, p. 14). This also echoes James March's call for a 'technology of foolishness' that embraces playful and non-purposive actions, to complement the rational 'technology of reason' that dominates management research (March, 1971; cf. also Sarasvathy and Dew, 2005). All systems that navigate in a complex and uncertain environment must to some degree rely on 'the heroism of fools and the blindness of true believers' (March, 2006, p. 201) in order to survive. History has shown that chance events and unreflective actions can yield radically new insights, precisely because they are not consciously planned (Campbell, 1960; Roberts, 1989).

While serendipity, unsubstantiated enthusiasm and 'foolishness' may be crucial for innovation, entrepreneurs should not engage in boundless unreflective action. The role of the $\mathrm{VC}$ must therefore include maintaining a mindful balance between planned experiments and unreflective activities (cf. Garud and Karnøe, 2001). Since VCs are in a position to exercise authority over their ventures, they are also in a good position to actively manage this trade-off. The most likely scenario is that entrepreneurs will want to take unreflective actions, based on vague intuitions or passion, and that the $\mathrm{VC}$ will have to decide how much of these to allow in view of the venture's other needs. Besides this passive role, the VC can actively support unreflective action, for instance by encouraging entrepreneurs to take actions and nurture relationships that are not obvious to them, but which may have the potential to generate future learning (cf. Lane and Maxfield, 1996).

Deciding when to allow or encourage unreflective actions is, of course, highly problematic - not least since VCs spend much of their very limited time making sure that their portfolio companies act in accordance with specific goals (Fried and Hisrich, 1995). Such decisions, much like the unreflective actions themselves, cannot 
be taken in a purely rational and analytical way. Therefore, it may be argued that this is an area where VCs are especially likely to rely on experience and intuition (cf. Zacharakis and Meyer, 1998).

\section{Unverified Assumptions}

The final arrow in Figure 1 depicts how entrepreneurs refine their pre-understanding without testing any assumptions in action. Such unverified assumptions may be either known or unknown. In the first instance, the entrepreneur essentially takes a calculated risk by chancing that an assumption is correct, thereby moving the venture forward without any test in action. If the assumption later proves to have been correct, the venture will have learned efficiently. Otherwise, the venture will also have learned in the sense that an assumption is rejected (Sull, 2004). But this strategy is potentially dangerous, especially for assumptions about critical issues such as the nature of customer preferences, the existence of competitors, or the strength of patents. Other reasons for leaving known assumptions untested include the cost or complexity of verification, as well as the risk of disclosing important information to competitors.

If, instead, unverified assumptions remain unknown, the entrepreneur will not know the premises on which the venture is built, possibly leading to disastrous results (cf. Stockport et al., 2001). In real life, multiple unverified assumptions are often operating simultaneously, and each of them may be either known or unknown. This complicates matters further, since the results from testing a known assumption could be confounded by one or more unknown factors. ${ }^{7}$ By the same token, however, such a test may be used to reveal those factors safely if steps are taken to limit potential damage.

Identifying the critical assumptions is a core entrepreneurial process, and here the VC's industry expertise is indispensable. This is especially true when exposing unknown assumptions in the venture, a task that requires familiarity not only with the venture's business, but also with its broader industrial context (Sapienza, 1992). The VC's more general venture development expertise is also important in terms of structuring and providing order to the learning process, for instance by keeping track of key assumptions and setting up milestones (cf. McGrath and MacMillan, 1995). By continuously reflecting on the venture and the assumptions underlying it, VCs can aid the systematic build-up of entrepreneurial pre-understanding, which also provides the basis for decisions to perform experiments or to take a chance that assumptions are correct.

\section{Summary and Conclusions}

We have drawn on two generic views of learning and scientific development to propose a theoretical model of entrepreneurial learning, and have used the model to illustrate how VCs may apply their industry-specific and general expertise to add value to their ventures after investments have been made. This has extended our understanding of the role and influence of venture capitalists - an area which has so far been mainly descriptive with few attempts at theoretical explanation (Wijbenga et al., 2003). 
In doing so, we have argued that knowledge is built up by incremental additions to propositional knowledge as well as by reflection on, and more systemic reformulation of, the foundations for acting in the world. Following received conceptual canons, we have referred to these approaches to learning as the hypothesis-testing mode and the hermeneutic mode respectively. The process of entrepreneurial learning has been conceptualized as an exchange between these two modes, each driving the other, mainly through entrepreneurial 'experimentation' and 'evaluation'. The hypothesis-testing mode may also be seen as action-oriented, while the hermeneutic mode constitutes a form of reflection (cf. Schön, 1983). This helps us to understand venture learning as a species of learning in general, including scientific learning and 'biological learning'. Both of these are often viewed as a form of blind variation and retentive selection, where the effects of phenotype 'experiments' are stored in the genetic memory of a lineage (Campbell, 1960; Hull, 1988).

We have further identified two potentially dysfunctional categories of learning, which are likely to be always present in, and sometimes crucial to, venture development: 'unreflective actions' and 'unverified assumptions'. We then used these four categories to analyse the varied roles VCs have in entrepreneurial learning. These roles were found to include transfer of foresight knowledge, elicitation of understanding, and the contribution of a sound platform for future learning activities. VCs were also seen to be crucial for helping entrepreneurs select among potential learning situations and for designing learning experiments. Moreover, VCs were found to be of key importance for monitoring entrepreneurs' unreflective actions and for identifying and breaking up dysfunctional self-referential reflection.

Finally, it has been argued that to understand the value of VCs' expertise and the nature of their value added, we need a rich comprehension of the entrepreneurial learning activities to which the VC seeks to contribute. Research should therefore continue to elaborate a model of entrepreneurial learning in order to clarify the role of venture capitalists.

\section{Notes}

1 In this paper the term 'entrepreneurial learning' is used to denote what may also be called 'venture learning', i.e. learning by the whole venture team.

2 General and specific VC expertise is often operationalized and measured as amounts of education and experience (Dimov and Shepherd, 2005). While this is in line with the present review, we focus on the contents of these two forms of VC expertise in an effort to explain theoretically how VCs may support the process of entrepreneurial learning.

3 There is an important discussion in entrepreneurship studies regarding relevant outcome measures (Davidsson, 2004), including whether the focus should be on learning and performance in specific ventures or in individual entrepreneurs (Sarasvathy, 2004). Therefore, it should be noted that the focus here is not on individual learning and knowledge build-up, but on venture development and the knowledge build-up necessary for developing specific ventures.

4 It may be worth noting that especially Alfred Schutz was close to many members of the Austrian school of economics, most notably Ludvig von Mises (cf. Kurrild-Klittgaard, 2003).

5 Baron's emphasis on cognitive prototypes and exemplars indicates an ontological position that is in many ways orthogonal to the hermeneutic tradition discussed here (cf. Berglund, 2006). Still, the description of the process of pattern-matching nicely illustrates the type of ill-structured and emergent learning that is the focus of our present discussion. 
6 To be fair, Schön also recognized the value of this distinction and complemented his notion of reflection-in-action with the more distanced reflection-on-action.

7 We would like to thank an anonymous reviewer for pointing this out.

\section{References}

Anderson, P. (1999) Venture capital dynamics and the creation of variation through entrepreneurship, in: J. A. C. Baum and B. McKelvey (Eds) Variations in Organization Science: In Honor of Donald T. Campbell, pp. 137-153 (Thousand Oaks, CA: Sage).

Ansoff, I. (1965) Corporate Strategy: An Analytical Approach to Business Policy for Growth and Expansion (New York: McGraw-Hill).

Baron, R. (2006) Opportunity recognition as pattern recognition: how entrepreneurs 'connect the dots' to identify new business opportunities, Academy of Management Perspectives, 20(1), pp. 104-119.

Baumol, W. (1968) Entrepreneurship in economic theory, American Economic Review, 58(2), pp. 64-71.

Berglund, H. (2006) Researching entrepreneurship as lived experience, in: H. Neergaard and J. Ulhöi (Eds) Handbook of Qualitative Research Methods in Entrepreneurship (Cheltenham, UK: Edward Elgar, forthcoming).

Bianchi, M. and Henrekson, M. (2005) Is neoclassical economics still entrepreneurless?, Kyklos, 58(3), pp. $353-377$.

Boettke, P., Lavoie, D. and Storr, V. (2004) The subjectivist methodology of Austrian economics and Dewey's theory of inquiry, in: E. Khalil (Ed.) Dewey, Pragmatism and Economic Methodology, pp. 327-356 (London: Routledge).

Brown, J. and Duguid, P. (1991) Organizational learning and communities of practice: toward a unified view of working, learning, and innovation, Organization Science, 2(1), pp. 40-57.

Busenitz, L. and Barney, J. (1997) Differences between entrepreneurs and managers in large organizations: biases and heuristics in strategic decision-making, Journal of Business Venturing, 12, pp. $9-30$.

Busenitz, L., Fiet, J. and Moesel, D. (2004) Reconsidering the venture capitalists' 'value added' proposition: an interorganizational learning perspective, Journal of Business Venturing, 19(6), pp. 787-807.

Campbell, D. (1960) Blind variation and selective retention in creative thought as in other thought processes, Psychological Review, 67, pp. 380-400.

Casamatta, C. (2003) Financing and advising: optimal financial contracts with venture capitalists, Journal of Finance, 58(5), pp. 2059-2086.

Cook, S. and Brown, J. (1999) Bridging epistemologies: the generative dance between organizational knowledge and organizational knowing, Organization Science, 10, pp. 381-400.

Davidsson, P. (2004) Researching Entrepreneurship (New York: Springer).

De Clercq, D. and Sapienza, H. (2001) The creation of relational rents in venture capitalist-entrepreneur dyads, Venture Capital, 3(2), pp. 107-128.

Dimov, D. and Shepherd, D. (2005) Human capital theory and venture capital firms: exploring 'home runs' and 'strike outs', Journal of Business Venturing, 20(1), pp. 1-21.

Fried, V. and Hisrich, R. (1995) The venture capitalist: a relationship investor, California Management Review, 37(2), pp. 101-114.

Gadamer, H. (1976) Philosophical Hermeneutics (Berkeley: University of California Press).

Gale, D. and Hellwig, M. (1985) Incentive-compatible debt contracts: the one-period problem, Review of Economic Studies, 52(4), pp. 647-633.

Gartner, W., Bird, N. and Starr, J. (1992) Acting as if: differentiating entrepreneurial from organizational behaviour, Entrepreneurship Theory and Practice, 16(3), pp. 13-31.

Gartner, W., Carter, N. and Hills, G. (2003) The language of opportunity, in: C. Steyaert and D. Hjorth (Eds) New Movements in Entrepreneurship, pp. 103-124 (London: Edward Elgar).

Garud, R. and Karnøe, P. (2001) Path creation as a process of mindful deviation, in: R. Garud and P. Karnøe (Eds) Path Dependence and Creation, pp. 1-38 (Mahwah, NJ: Lawrence Erlbaum Associates).

Gifford, S. (1997) Limited attention and the role of the venture capitalist, Journal of Business Venturing, 12, pp. $459-482$.

Gomez-Mejia, L., Balkin, D. and Welbourne, T. (1990) Influence of venture capitalists on high tech management, Journal of High Technology Management Research, 1(1), pp. 103-118. 
Grossman, S. and Hart, O. (1986) The costs and benefits of ownership: a theory of vertical and lateral integration, Journal of Political Economy, 94(4), pp. 691-719.

Harper, D. (1996) Entrepreneurship and the Market Process: An Enquiry into the Growth of Knowledge (New York: Routledge).

Harper, D. (1999) How entrepreneurs learn: a Popperian approach and its limitations, Working Paper 99-3, Copenhagen Business School (Denmark: Department of Industrial Economics and Strategy).

Hayek, F. (1978) Competition as a discovery procedure, in: F. Hayek New Studies in Philosophy, Politics, Economics and the History of Ideas, pp. 179-190 (Chicago: University of Chicago Press).

Hellmann, T. (2000) Venture capitalists: the coaches of Silicon Valley, in: C.-M. Lee, W. F. Miller, M. G. Hancock and H. S. Rowen (Eds) The Silicon Valley Edge, pp. 276-294 (Stanford: Stanford University Press).

Hellström, T., Hellström, C. and Berglund, H. (2002) The innovating self: exploring self among a group of technological innovators, Journal of Managerial Psychology, 17(4), pp. 267-286.

Hull, D. (1988) Science as a Process (Chicago: Chicago University Press).

Jungwirth, C. and Moog, P. (2004) Selection and support strategies in venture capital financing: high-techs or low-techs, hands-off or hands-on?, Venture Capital, 6(2/3), pp. 105-123.

Kirzner, I. (1973) Competition and Entrepreneurship (Chicago: The University of Chicago Press).

Kirzner, I. (1997) Entrepreneurial discovery and the competitive market process: an Austrian approach, Journal of Economic Literature, 35(1), pp. 60-85.

Kurrild-Klittgaard, P. (2003) The Viennese connection: Alfred Schutz and the Austrian school, Quarterly Journal of Austrian Economics, 6(2), pp. 35-67.

Lane, D. and Maxfield, R. (1996) Strategy under complexity: fostering generative relationships, Long Range Planning, 29, pp. 215-231.

Lavoie, D. (1986) The market as a procedure for discovery and conveyance of inarticulate knowledge, Comparative Economic Studies, 28(1), pp. 1-19.

Lavoie, D. (Ed.) (1990) Economics and Hermeneutics (London: Routledge).

Lavoie, D. (1991) The discovery and interpretation of profit opportunities: culture and the Kirznerian entrepreneur, in: B. Berger (Ed.) The Culture of Entrepreneurship, pp. 33-51 (San Francisco: Institute for Contemporary Studies).

McGrath, R. and MacMillan, I. (1995) Discovery-driven planning, Harvard Business Review, 73(4), pp. $44-54$.

MacMillan, I., Kulow, D. and Khoylian, R. (1989) Venture capitalists' involvement in their investments: extent and performance, Journal of Business Venturing, 4(1), pp. $27-47$.

March, J. (1971) The technology of foolishness, Civilökonomen, 4, pp. 4-12.

March, J. (2006) Rationality, foolishness, and adaptive intelligence, Strategic Management Journal, 27(3), pp. $201-214$.

Minniti, M. and Bygrave, W. (2001) A dynamic model of entrepreneurial learning, Entrepreneurship Theory and Practice, 25, pp. 5-16.

Monsted, M. (2006) High-tech, uncertainty and innovation: the opportunity for high tech entrepreneurship, in: M. Bernasconi, S. Harris and M. Monsted (Eds) High-Tech Entrepreneurship. Managing Innovation, Variety and Uncertainty, pp. 15-32 (London and New York: Routledge).

Popper, K. (1963) Conjectures and Refutations (London: Routledge \& Kegan Paul).

Roberts, R. (1989) Serendipity: Accidental Discoveries in Science (New York: John Wiley \& Sons).

Sapienza, H. (1992) When do venture capitalists add value?, Journal of Business Venturing, 7(1), pp. $9-28$.

Sarasvathy, S. (2001) Causation and effectuation: towards a theoretical shift from economic inevitability to entrepreneurial contingency, Academy of Management Review, 26(2), pp. 243-288.

Sarasvathy, S. (2004) The questions we ask and the questions we care about: reformulating some problems in entrepreneurship research, Journal of Business Venturing, 19(5), pp. 707-717.

Sarasvathy, S. and Dew, N. (2005) Entrepreneurial logics for a technology of foolishness, Scandinavian Journal of Management, 21, pp. 385-406.

Schön, D. (1983) The Reflective Practitioner. How Professionals Think in Action (London: Temple Smith).

Schutz, A. and Luckmann, T. (1973) The Structures of the Life-World (Evanston: Northwestern University Press).

Shane, S. (2000) Prior knowledge and the discovery of entrepreneurial opportunities, Organization Science, 11(4), pp. $448-469$ 
Shane, S. and Venkataraman, S. (2000) The promise of entrepreneurship as a field of research, Academy of Management Journal, 25, pp. 217-226.

Sitkin, S. (1992) Learning through failure: the strategy of small losses, Research in Organizational Behavior, 14, pp. $231-266$.

Sjögren, H. and Zackrisson, M. (2005) The search for competent capital: financing of high technology small firms in Sweden and USA, Venture Capital, 7(1), pp. 75-97.

Stockport, G. J., Kunnath, G. and Sedick, R. (2001) Boo.com - the path to failure, Journal of Interactive Marketing, 15(4), pp. 56-70.

Sull, D. (2004) Disciplined entrepreneurship, Sloan Management Review, 46(1), pp. $71-77$.

Sull, D. (2005) Strategy as active waiting, Harvard Business Review, 83(12), pp. $121-129$.

Timmons, J. and Bygrave, W. (1986) Venture capitalist's role in financing innovation for economic growth, Journal of Business Venturing, 1(2), pp. 161-176.

Weick, K. (1979) The Social Psychology of Organizing (New York: McGraw-Hill).

Weick, K., Sutcliffe, K. and Obstfeld, D. (2005) Organizing and the process of sensemaking, Organization Science, 16(4), pp. 409-421.

Wijbenga, F., Postma, T., Van Witteloostuijn, A. and Zwart, P. (2003) Strategy and performance of new ventures: a contingency model of the role and influence of the venture capitalist, Venture Capital, 5(3), pp. $231-250$.

Yin, R. (1994) Case Study Research: Design and Methods, 2nd edn (Newbury Park, CA: Sage Publications).

Zacharakis, A. and Meyer, G. (1998) A lack of insight: do venture capitalists really understand their own decision process?, Journal of Business Venturing, 13, pp. 57-76. 